contrada fator determinante na gênese da IUE, e sua elevada freqüência em ambos os grupos do estudo sugere que possa ser um polimorfismo de nucleotídeo único em nossa população. É discutido qual dos demais exons não pesquisados teria maior probabilidade de alojar a mutação postulada.

Palavras-chave: Incontinência urinária; Elastina; Assoalho pélvico; Mutações; Reação em cadeia da polimerase

Resumo de Tese

\title{
Genotipagem RHD através da análise do plasma materno
}

\section{Fetal RHD genotyping by analysis of the maternal plasma}

Autora: Isabela Nelly Machado

Orientador: Prof. Dr. Ricardo Barini

Co-orientadora: Prof ${ }^{a} \operatorname{Dr}^{\mathrm{a}}$ Lilian Castilho

Dissertação de Mestrado apresentada à Pós-Graduação da Faculdade de Ciências Médicas da Universidade Estadual de Campinas (UNICAMP), Departamento de Tocoginecologia, em 11 de agosto de 2004.

Introdução: a determinação da tipagem sanguinea $\mathrm{RhD}$ fetal é útil para o acompanhamento pré-natal das gestantes RhD-negativo, sensibilizadas ou não, evitandose desnecessários procedimentos invasivos na presença de fetos RhD-negativo. A análise molecular do plasma materno abriu novas possibilidades para o diagnóstico pré-natal não invasivo, onde a genotipagem $R H D$ fetal é uma das aplicações clínicas mais relevantes até o momento. Objetivo: Avaliar o desempenho da genotipagem $R H D$ fetal através da análise do plasma materno como método diagnóstico pré-natal não invasivo. Método: estudo de validação de teste diagnóstico a partir de 81 amostras sangüíneas obtidas de gestantes RhD-negativo, entre 4 e 41 semanas de gestação. $\mathrm{O}$ DNA fetal foi extraído dos respectivos plasmas maternos, e as regiões exon 10 e intron 4 do gene RHD foram testadas através da reação em cadeia da polimerase alelo-específica (AS-PCR) convencional. Os resultados da genotipagem fetal foram comparados com a tipagem sanguínea neonatal. Resultados: 15 amostras foram obtidas no primeiro trimestre, 37 no segundo trimestre e 29 no terceiro trimestre. Houve falha de amplificação em seis amostras, três RhD-negativo e três RhD-positivo à tipagem neonatal. A concordância entre os resultados da genotipagem e da tipagem neonatal foi de $97,3 \%$, com sensibilidade de $98,3 \%$ e especificidade de $93,8 \%$. Foi observado um falso positivo no terceiro trimestre e um falso negativo no primeiro trimestre. Conclusão: AS-PCR convencional através da análise do plasma materno é um método que pode ser usado com confiabilidade e segurança para a genotipagem $R H D$ fetal.

PALAVRAS-CHAVE: Isoimunização Rh; Genotipagem fetal; Diagnóstico pré-natal

Trabalho financiado pela Fundação de Amparo à Pesquisa do Estado de São Paulo (FAPESP), processo número 2002/ 08930-2.

Correspondência:

Rua Jasmim, 28, Apto 504, BlocoA.

13087-520 - Campinas - SP

Telefone: (19) 3296-0482

e-mail: imachado@fcm.unicamp.br

Pharmacokinetic and stereoselectivity of bupivacaine in normal pregnant women who were submitted to epidural anesthesia for cesarean section.

Autora: Luciana de Barros Duarte

Orientador: Prof. Dr. Sérgio Pereira da Cunha

Dissertação de Mestrado apresentada à Faculdade de Medicina de Ribeirão Preto - Universidade de São Paulo Departamento de Ginecologia e Obstetrícia, em 20 de agosto de 2004.

Resumo: O objetivo do presente estudo é avaliar a enantiosseletividade na disposição cinética e na transferência transplacentária da bupivacaina em gestantes normais. Foram avaliadas dez gestantes, submetidas a parto cesáreo eletivo e à anestesia epidural. Amostras de sangue materno foram colhidas em intervalos progressivos de tempo, iniciadas no momento da indução anestésica até $14 \mathrm{~h}$ após o procedimento. Adicionalmente foi colhida uma única amostra da veia umbilical fetal. A análise dos parâmetros farmacocinéticos evidenciou: valor de clearance maior para o enantiômero (+)-(R) 32,95 vs 25,52 L/h em relação ao (-)-(S) com diferença estatisticamente significante $\mathrm{p}<0,05$. Valores de a encontrados foram 0,83 vs $1,18 \mathrm{~h}^{1}$ 